\title{
DETERMINATION OF CRITICAL SIZE OF CORROSION PIT ON MECHANICAL ELEMENTS IN HYDRO POWER PLANTS
}

UDC: $621.311 .21: 624.042 .62$

Original scientific paper

https://doi.org/10.18485/aeletters.2018.3.1.1

\author{
Radivoje M. Mitrović ${ }^{1}$, Dejan B. Momčilović ${ }^{2}$, Ivana D. Atanasovska ${ }^{3}$ \\ ${ }^{1}$ University of Belgrade, Faculty of Mechanical Engineering, Serbia \\ ${ }^{2}$ Institute IMS, Belgrade, Serbia \\ ${ }^{3}$ Mathematical Institute of the Serbian Academy of Sciences and Arts, Belgrade, Serbia
}

\begin{abstract}
:
Researchers in the field of fracture mechanics, predominantly developing appropriate solution algorithms for problems of solid bodies with cracks. Problems in mechanics generally, related with fracture and fatigue for solid bodies with various geometries of sharp notches, are studied to a much lesser extent. This situation can be explained by analytical difficulties arising in solving problems of elasticity theory for bodies with rounded notches. To solve problems of such class, starting from data on stress concentration in the rounded notch tip with a significant radius of curvature, simplified solutions with are therefore of great importance. Recent years, due to constant rise of computing power and development of numerical methods, re-evaluation of stress concentration factors from a viewpoint of theory of elasticity is present. This is mainly as a feedback from industry, which have requirements toward mega and nanostructures.

Corrosion represents an important limitation to the safe and reliable use of many alloys in various industries. Pitting corrosion is a form of serious damage on metals surface such as high-strength aluminum alloys and stainless steel, which are susceptible to pitting when exposed to a corrosive attack in aggressive environments. This is particularly valid for dynamic loaded structures.

The basic idea behind this paper is finding links between different scientific and engineering disciplines, which will enable useful level of applicability of existing knowledge. The subject of this paper is application of new method of determine length scale parameter for estimating the mechanistic aspect of corrosion pit under uniaxial/multiaxial high-cycle fatigue loading...
\end{abstract} ARTICLE HISTORY

Received 05.01.2018

Accepted 27.02.2018

Available 15.03.2018

\section{KEYWORDS}

stress concentration, fatigue,

multiaxial fatigue,

corrosion pit,

critical distance.

\section{INTRODUCTION}

The variation of complex geometries on real mechanical components is in direct relation with local stress concentration phenomena. During recent years different theories have been developed to particularly perform the high-cycle fatigue assessment of notched components without missing the undoubted advantages of linear-elastic finite element solutions.
The magnitude of fatigue damage can be quantified also in terms of linear-elastic notch tip stresses, taking into consideration the high-cycle fatigue only. The advantage of this simplification is that linear-elastic notch root stresses can easily be determined via conventional linear-elastic finite element (FE) models. The main drawback is that this methodology is very straightforward, the resulting level of conservatism is seen to increase as the sharpness of the geometrical feature being 
assessed increases. Consequently, under relatively large values of the stress concentration factors, this leads to components and structures which are heavier and bigger than necessary, with an end result of inefficient usage of materials and energy efficiency. Further, this simplified approach cannot be used to design against fatigue cracks and sharp notches, because the resulting linear-elastic local stress fields become singular when crack/notch tip radii are taken equal to zero. The problem increase with complex three dimensional geometries on components subjected with uniaxial/multiaxial loading [1]. Some of the answers for noted problems are solved by Theory of Critical Distances (TCD). TCD represents a family of methods that are all characterized by two main common features: (i) the relevant stress fields are determined by adopting a simple linear-elastic constitutive law to model the mechanical behavior of the material being assessed; (ii) the extent of damage is assessed via an effective stress whose value depends not only on the entire linear-elastic stress fields acting on the material in the vicinity of the crack initiation locations, but also on a material characteristic length [2-4].

The TCD can be applied solely to notches subjected to in-service Mode I fatigue loading. In order to extend its use to those situations involving complex multiaxial load histories, this approach has to be applied along with an appropriate multiaxial fatigue damage model. Researchers [1] has been proven that the highest level of accuracy is obtained by applying the PM along with the socalled Modified Wöhler Curve Method (MWCM) $[5,6]$ and gradient elasticity [7-10], through length scale parameter $\ell$ (1). The MWCM is a biparametrical critical plane approach, the critical plane being that material plane experiencing the maximum shear stress amplitude ta. The MWCM quantifies the extent of fatigue damage not only via ta, but also via the mean value, on, $m$, and the amplitude, on,a, of the stress perpendicular to the critical plane. Recent efforts [7-10] in the mechanics, materials science, and applied physics communities have introduced internal length in phenomenological gradient models to account for internal micro/nanostructures and derive, among other things, non-singular analytical expressions for dislocation/crack fields, as well as to interpret deformation localization phenomena (shear bands, dislocation patterns) along with size effects. As a result further development can be expected by combining gradient elasticity with TCD and MWCM. As to a possible way to determine length scale parameter $\ell$, it is evident that gradient elasticity and the TCD share some important features. In particular, both approaches postprocess the relevant stress fields by coupling linerelasticity with an internal length scale parameter which is assumed to be an intrinsic material property. By taking as a starting point these similarities, recently it was proven that length $l$ can directly be estimated from the TCD's critical distance $L$ as follows (1):

$$
\ell \approx \frac{L}{2 \sqrt{2}}=\frac{1}{2 \sqrt{2} \pi}\left(\frac{\Delta K_{t b}}{\Delta \sigma_{0}}\right)^{2}
$$

Previous equation points that length scale parameter $l$ can directly be estimated from the material plain fatigue limit, $\sigma 0$, and the threshold value of the stress intensity factor range, Kth, or through known value of critical distance $L$. Because both $\sigma 0$ and Kth are material properties, $\ell$ is in turn an intrinsic characteristic length which is different for different materials and different load ratios.

Published results show that gradient elasticity was seen to be capable of accurately modeling, in the fatigue limit condition, the transition from the short to the long-crack regime [11]. Moreover, gradient elasticity applied along with the MWCM was successful in assessing the high cycle fatigue strength of specimens, the estimates falling within an error interval of $\pm 20 \%$.

The results in this field open field of application on corrosion fatigue damage assessment. Example for this application is given in $[12,13]$ which is good example of real component subjected to both uniaxial and multiaxial fatigue loading, with stress concentration - corrosion pit on transition radius, Fig.1. Detail of damage caused by corrosion on transition zone is shown on Fig.2.

\section{DESCRIPTION OF APPLIED METHODOLOGY}

The theory of critical distances (TCD) has named by Taylor [2] attempts to predict the effect of notches and other stress concentration features by considering the stress field in the region close to the notch tip. This theory requires two parameters, a characteristic distance and a critical stress or strain characterizing failure. In one version of the critical distance theory, termed as the Point Method, the failure occurs when the stress becomes equal to the failure stress at a given distance from the notch root. In the other version of the critical distance theory, termed as the Line Method, the failure is assumed to occur when the stress becomes equal to the failure stress when 
computed as an average value over a line of given length.

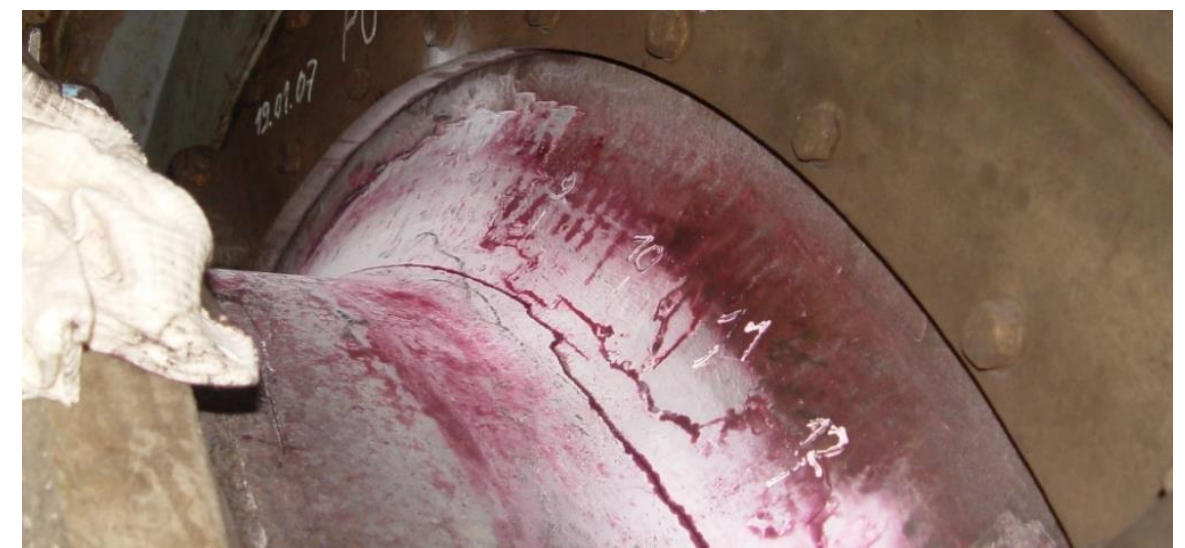

Fig.1. General view of cracks initiated from on transition radius and meshing on hydro turbine shaft

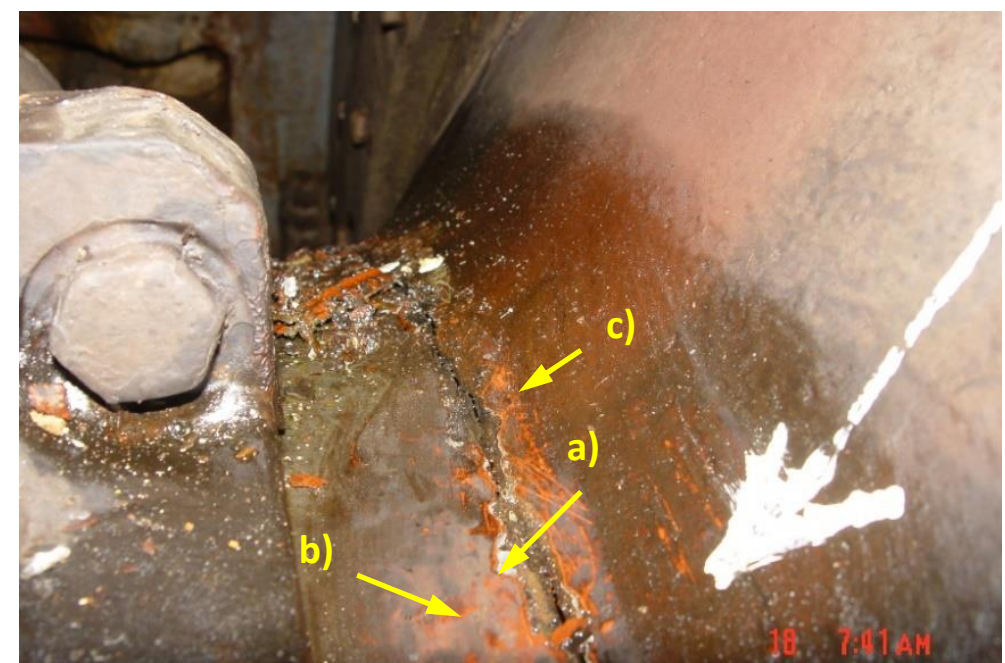

Fig.2. Close view of the transient flange radius after detecting the crack a) main crack, b) anti-corrosive protection layer, c) oil residue on corrosion pits

The background philosophy lying behind the TCD is described as wish to observe engineering components rather than to test specimens. In practice this meant that we only considered predictive methods which could be applied to bodies of arbitrary shape and size, subjected to arbitrary loadings, containing stress concentration features of arbitrary geometry. This is achieved by measuring material behavior using test specimens containing notches rather than cracks (fatigue threshold $\Delta K$ th and toughness $K c$ using sharp notches rather than pre-cracks) which avoids the difficulties and uncertainties of carrying out standard fracture mechanics tests. The second presumption of successful application of TCD is the existence of an accurate stress analysis of the machine part.

The analysis and assessment of influence of corrosion pit depth on crack initiation was discussed [12-15]. The analysis of the stresses on various dimensions of pits on numerical model, (Fig.3 and Fig.4a) was used to evaluate a critical depth of pit for this particular case, (Fig.4b).
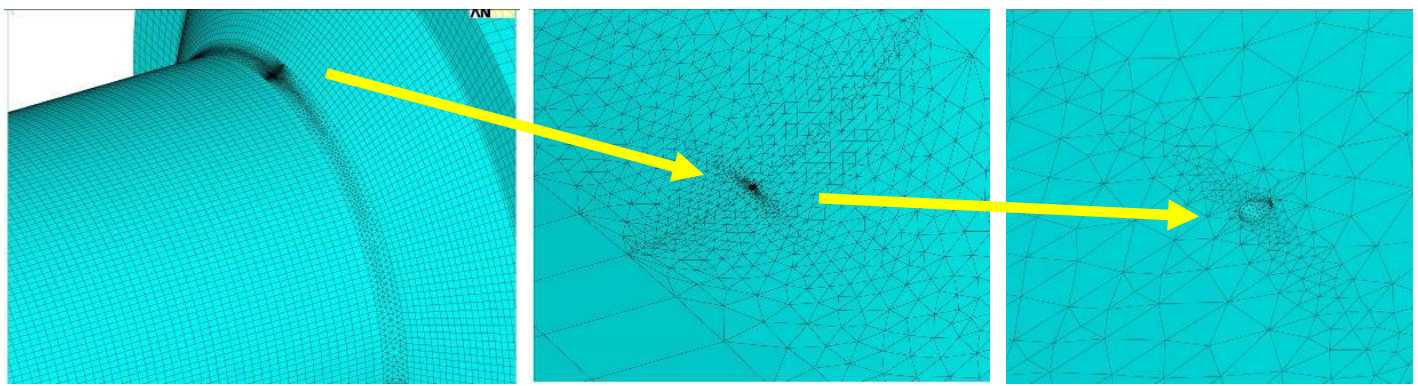

Fig.3. Meshing on hydro turbine shaft. Model of $300 \mu \mathrm{m}$ radius corrosion pit on $7000 \mathrm{~mm}$ long model of turbine shaft. 


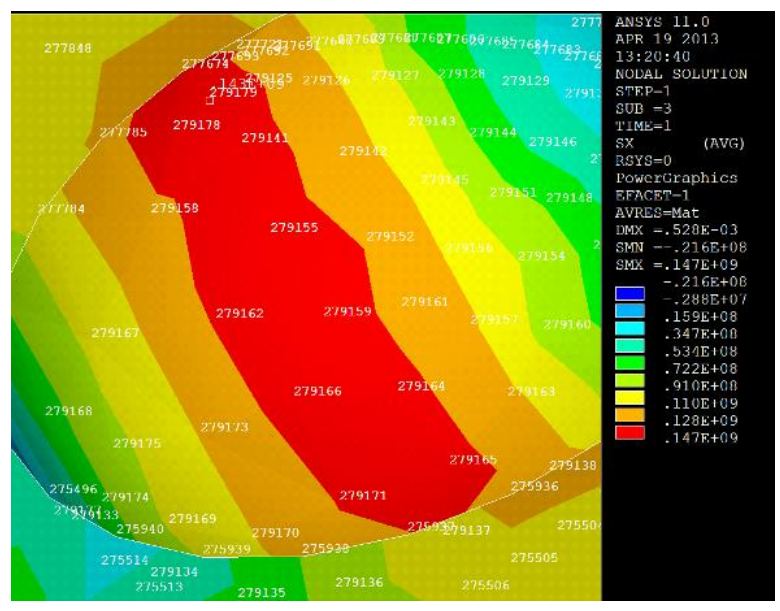

a)

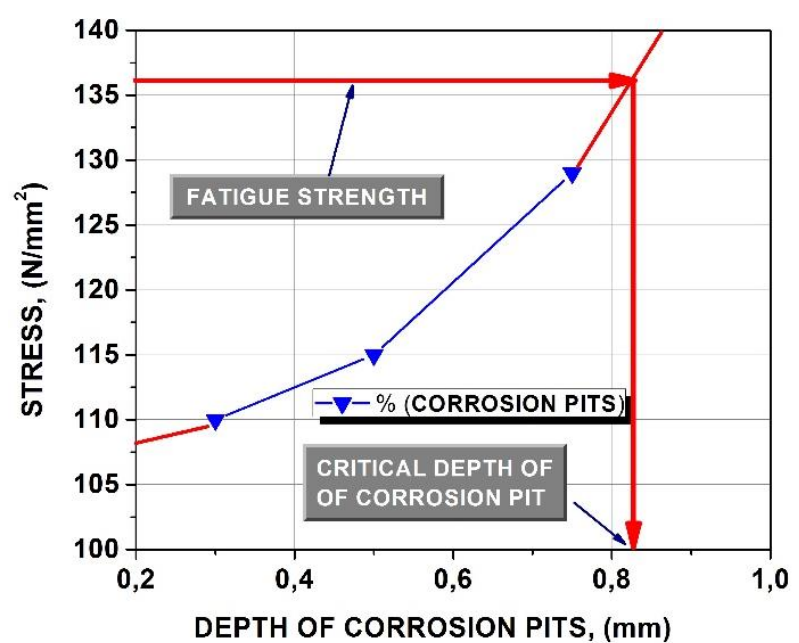

b)

Fig.4. Solution for corrosion pit for $r=300 \mu \mathrm{m}$ pit, distance between nodes 277674 and 279165 is $340 \mu \mathrm{m}$ a) detail with results; b) extrapolated values of analyzed corrosion pits with marked critical value of corrosion pit

\section{CONCLUSION}

From the presented and promising results, the general conclusions from gradient elasticity point of view are:

Identification and determination length scale parameter through solid physics arguments from phenomena like fatigue, mechanism-based microscopic models, multiscale simulations, and experiments, presents the way of enhancing present knowledge of stress concentration.

This is important due fact that coupling gradient elasticity applied along with the MWCM is highly accurate in estimating high-cycle fatigue strength of notched components subjected to both uniaxial and multiaxial fatigue loading. It is also important to underline that application on real components require further research in this area to extend the use of the proposed methodology to the finite lifetime regime.

\section{REFERENCES}

[1] M.P. Savruk, A. Kazberuk, Stress Concentration at Notches. Springer, 2016.

https://doi.org/10.1007/978-3-319-44555-7

[2] D. Taylor, The theory of critical distances: a new perspective in fracture mechanics. Elsevier, 2010.

[3] L. Susmel, The theory of critical distances: a review of its applications in fatigue. Engineering Fracture Mechanics, 75 (7), 2008: 1706-1724.

https://doi.org/10.1016/j.engfracmech.2006.12.004

[4] L. Susmel, D. Taylor, Can the conventional high-cycle multiaxial fatigue criteria be re- interpreted in terms of the theory of critical distances?. SDHM, 2 (2), 2006: 91-108.

[5] L. Susmel, D. Taylor, The modified Wöhler curve method applied along with the theory of critical distances to estimate finite life of notched components subjected to complex multiaxial loading paths. Fatigue \& Fracture of Engineering Materials \& Structures, 31 (12), 2008: 1047-1064.

https://doi.org/10.1111/j.1460-2695.2008.01296.x

[6] L. Susmel, Multiaxial notch fatigue. Elsevier, 2009.

[7] H. Askes, P. Livieri, L. Susmel, D. Taylor, R. Tovo, Intrinsic material length, Theory of Critical Distances and Gradient Mechanics: analogies and differences in processing linearelastic crack tip stress fields. Fatigue \& Fracture of Engineering Materials \& Structures, 36 (1), 2013: 39-55.

https://doi.org/10.1111/i.1460-2695.2012.01687.x

[8] L. Susmel, H. Askes, T. Bennett, D. Taylor, Theory of critical distances versus gradient mechanics in modelling the transition from the short to long crack regime at the fatigue limit. Fatigue \& Fracture of Engineering Materials \& Structures, 36 (9), 2013: 861-869. https://doi.org/10.1111/ffe.12066

[9] E. C. Aifantis, Gradient material mechanics: perspectives and prospects. Acta Mechanica, 225 (4-5), 2014: 999-1012.

https://doi.org/10.1007/s00707-013-1076-y

[10] T. J. Charlton, W. M. Coombs, C. E. Augarde, Gradient elasticity with the material point method. Cardiff University, 2016.

[11] C. Bagni, H. Askes, L. Susmel, Gradient elasticity: a transformative stress analysis tool 
to design notched components against uniaxial/multiaxial high-cycle fatigue. Fatigue \& Fracture of Engineering Materials \& Structures, 39 (8), 2016: 1012-1029.

https://doi.org/10.1111/ffe.12447

[12] D. Momčilović, Z. Odanović, R. Mitrović, I. Atanasovska, T. Vuherer, Failure analysis of hydraulic turbine shaft. Engineering failure analysis, 20 (-), 2012: 54-66.

https://doi.org/10.1016/i.engfailanal.2011.10.006

[13] D. Momčilović, R. Mitrović, I. Atanasovska, Stress Concentration and Fatigue of Materials (In Serbian). Faculty of Mechanical Engineering, University of Belgrade, 2016.

[14] I. Atanasovska, M. Jelić, R. Mitrović, D. Momčilović, The Influence of Corrosion on Stress Concentration Factor at Shaft to Flange Radius. In: Dobre G. (eds) Power Transmissions. Mechanisms and Machine Science, Vol.13. Springer, Dordrecht, 2013. https://doi.org/10.1007/978-94-007-6558-0 53

[15] R. Mitrovic, D. Momcilovic, I. Atanasovska, Assessment of the Effect of Pitting Corrosion on Fatigue Crack Initiation in Hydro Turbine Shaft. Advanced Materials Research, 633 (-), 2013: 186-196.

https://doi.org/10.4028/www.scientific.net/AMR.63 $\underline{3.186}$

\section{ACKNOWLEDGEMENT}

Parts of this research were supported by the Ministry of Sciences and Technology of Republic of Serbia through Projects TR 35029 and TR 35011.

The shorter version of this research was presented at the " 8 nd International Scientific Conference IRMES 2017", 7 - 9 September 2017, Trebinje, Bosnia and Hercegovina. 